\title{
The effect of anticonvulsant use on bone mineral density in non-ambulatory children with cerebral palsy
}

\author{
SW Cheng *, CH Ko, CY Lee
}

\section{A B S T R A C T}

Introduction: Studies showed that use of anticonvulsants (antiepileptic drugs) might be associated with reduced bone mineral density. The primary objective of this study was to evaluate the effect of anticonvulsants on bone mineral density in non-ambulatory children with cerebral palsy. The secondary objective was to identify their risk factors for low bone mineral density.

Methods: This case series with internal comparisons was conducted in a paediatric residential rehabilitation centre in Hong Kong. Overall, 32 patients were enrolled. The study group comprised 18 patients (6 males, 12 females) aged 5.0 to 19.5 years (mean \pm standard deviation, $13.8 \pm 4.7$ years); all were prescribed anticonvulsant therapy for more than 2 years. The comparison group comprised 14 patients (6 males, 8 females) aged 7.0 to 19.1 years (mean, 16.4 \pm 3.0 years) who were concomitant nonambulatory residents with cerebral palsy and were not prescribed any anticonvulsant therapy prior to study recruitment. Patients underwent a physical examination, blood tests, nutritional assessment, and dual-energy X-ray absorptiometry scan of the total body less head. Z-scores were calculated.

This article was published on 6 May 2016 at www.hkmj.org.
Results: There was no significant difference in Zscores of total body less head between groups. Among children with low bone mineral density
(Z-scores $\leq-2.0)$ and normal bone mineral density, multivariate analysis revealed that higher weightfor-age Z-score (adjusted odds ratio=0.015) and presence of puberty (adjusted odds ratio $=0.027$ ) were independent factors for bone mineral density improvement. Hosmer-Lemeshow goodness of fit test $(\mathrm{P}=0.315)$ was not significant. Nagelkerke $\mathrm{R}^{2}$ was 0.677 , signifying a relatively well-fitting model.

Conclusion: There was no evidence that anticonvulsant therapy has any detrimental effect on bone mineral density in non-ambulatory children with cerebral palsy. A low weight-for-age Z-score was associated with low bone mineral density. Early nutritional intervention to optimise body weight may help to increase bone mineral density.

\section{Hong Kong Med J 2016;22:242-8}

DOI: $10.12809 / \mathrm{hkmj} 154588$

SW Cheng *, DPD (Cardiff), MRCPCH

CH Ko, FHKAM (Paediatrics), FRCP (Glasg)

CY Lee, FHKAM (Paediatrics), FRCP (Edin)

Department of Paediatrics and Adolescent Medicine, Caritas Medical Centre, Shamshuipo, Hong Kong

* Corresponding author: shirley.s.cheng@gmail.com

\section{New knowledge added by this study}

- Anticonvulsant use shows no significant and detrimental impact on bone mineral density (BMD) of nonambulatory cerebral palsy children.

- A low weight-for-age Z-score was found to be a significant independent risk factor predictive of low BMD. Implications for clinical practice or policy

- Optimal pharmacological treatment for epilepsy control can be pursued without jeopardising bone mineralisation in non-ambulatory cerebral palsy children.

- Optimising nutritional status in this group of children is important in improving bone mineralisation and thus decreasing pathological fracture.

\section{Introduction}

Osteoporosis is a skeletal disorder characterised by low bone mass and micro-architectural deterioration of bone tissue that results in compromised bone strength and a predisposition to fracture. ${ }^{1}$ Childhood and adolescence are critical periods for bone mineralisation. Peak bone mineral density (BMD) achieved by early adulthood determines the risk of pathological fracture. Bone mass can be objectively measured by BMD and is correlated with risk of osteoporotic fracture. ${ }^{2}$

Dual-energy X-ray absorptiometry (DXA) scanning enables cost-effective quantitative measurement of BMD. Such methodology is the gold 
standard because it can detect bone mineral loss of $2 \%$ to $5 \%$. Abnormal homeostasis of vitamin D, calcium, and phosphorous may lead to imbalanced osteoclastic and osteoblastic dynamics that will result in osteopenia and even osteoporosis. There have been reports from large- and small-scale studies of problems in bone mineralisation and vitamin $\mathrm{D}$ or calcium metabolism in patients with cerebral palsy (CP). ${ }^{3,4}$ Dietary restrictions, oromotor dysfunction, malabsorption, and limited sunlight exposure may lead to poor nutrition, low calcium intake, or altered vitamin $\mathrm{D}$ metabolism. These in turn contribute to poor mineralisation. Limited weight-bearing during the period of skeletal growth may also lead to reduced BMD. Chronic therapy with antiepileptic drugs (AEDs) may cause hypocalcaemia, hypophosphataemia, raised serum alkaline phosphatase, elevated serum parathyroid hormone, reduced biologically active vitamin $\mathrm{D}$ metabolites, rickets, and osteomalacia. The mechanism is unclear, however. ${ }^{5}$

A study revealed that AED use was associated with reduced BMD in 35 pairs of twin adults, and the effect was more marked in those prescribed enzyme-inducing AEDs, for example, phenytoin and phenobarbitone. ${ }^{6}$ A decrease in BMD (in $\mathrm{g} / \mathrm{cm}^{2}$ ) of $6.4 \%$ and $4.6 \%$ at the lumbar spine and femoral neck respectively in their twin control pair was detected. For valproate, the effect was not consistently demonstrated. ${ }^{7,8}$

Chronic treatment with AEDs was observed to be significantly correlated with a lower BMD in 96 ambulatory children and young adults with epilepsy with a mean Z-score of -1.23 compared with 0.16 of a control group. ${ }^{9}$ In our retrospective study of $109 \mathrm{CP}$ children in 2006, however, we could not demonstrate any association of AEDs with increased fracture rate in non-ambulatory $\mathrm{CP}$ children. ${ }^{10}$ In children with CP and a Gross Motor Function Classification System (GMFCS) level of 4 to 5 (bed-bound), the possible impact of anticonvulsants on BMD was not clearly demonstrated.

The primary objective of this study was to evaluate the effect of AEDs on BMD in nonambulatory children with $\mathrm{CP}$. The secondary objective was to identify the risk factors for low $\mathrm{BMD}$ in this group of children.

\section{Methods}

\section{Subjects}

Patients at the Developmental Disabilities Unit (DDU) of Caritas Medical Centre, Hong Kong were enrolled in the study from 1 October 2012 to 30 September 2013. The DDU is the largest long-term care facility for children with severe developmental disabilities and special health care needs in Hong Kong. Among the 100 residents, over $90 \%$ were nonambulatory and over $50 \%$ had CP.

\section{抗癲痌藥物對臥床的小兒腦癱患者骨密度的} 景響

鄭斯穎、高震雄、李靜賢

引言：研究顯示使用抗癲痾藥物可能與骨密度下降相關。本研究主要 評估抗癲瘑藥物對於臥床的小兒腦瘔患者骨密度的作用, 其次找出引 致患者低骨密度的危險因素。

方法：這個具內部比較的病例系列於香港一所兒科寄宿康復中心內 進行。研究對象為32名患者。實驗組有18例（6男12女），年齡介乎 5.0 至 19.5 歲（平均年齡 13.8 歲，標準差 4.7 歲）。他們均已接受抗癲 疡治療超過兩年。對照組有 14 例（6男8女），年齡介乎 7.0 至 19.1 歲 （平均年齡 16.4歲, 標準差3.0歲），他們同樣是臥床的小兒腦癱患 者, 但在研究前並無接受任何抗癲㾶治療。所有患者接受身體檢查、

驗血、營養評估, 以及不包括頭部的全身雙能X線骨密度掃描, 並計 算其Z值。

結果 : 兩組間不包括頭部的全身雙能X線骨密度掃描的Z值無顯著差 異。多變量分析顯示在低骨密度 (Z值 $\leq-2.0)$ 和正常骨密度的患者 中, 較高的按年齡體重的Z值 (調整後比值比 $=0.015)$ 和進入青春期 與否（調整後比值比 $=0.027$ ) 為骨密度改善的獨立因素。HosmerLemeshow擬合優度並不顯著（ $\mathrm{P}=0.315 ） 。$ Nagelkerke $\mathrm{R}^{2}$ 為0.677， 顯示模型對擬合度較好。

結論：沒有證據顯示抗癲㾍藥物對臥床的小兒腦癱患者骨密度有不良 影響。按年齡體重的Z值低與低骨質密度有關。及早作營養干預來優 化體重可能有助患者增加骨密度。

The inclusion criteria in this study were: (1) children and adolescents aged between 5 and 19 years; (2) GMFCS level 4 or 5 ; (3) the presence of spastic or mixed spastic dyskinetic CP; and (4) prescribed AED for more than 2 years.

The control group without anticonvulsant therapy comprised concomitant non-ambulatory DDU residents with $\mathrm{CP}$ who were not prescribed AEDs for more than 2 years prior to recruitment to the study.

The exclusion criteria included (1) GMFCS level of 1 to 3; (2) patients with underlying hepatic or renal disease; (3) presence of disease primarily involving bone metabolism or a family history of bone metabolic disorders; (4) known thyroid or parathyroid disease; (5) history of pathological long bone fracture; (6) history of chronic diarrhoea or malabsorption; (7) long-term intake of the following medications: non-physiological dose of glucocorticoid, anabolic steroid, vitamin A, nonsteroidal anti-inflammatory drugs, bisphosphonates, thiazide diuretics, or calcitonin.

\section{Sample size estimation}

Coppola et $\mathrm{al}^{9}$ reported a mean BMD Z-score of -1.23 and 0.16 in 96 ambulatory epileptic patients and 63 controls, respectively. In 2012, the same group showed the mean Z-score to be $-1.69(n=47)$ 
and $-0.83(\mathrm{n}=40)$ respectively in mentally retarded children with $\mathrm{CP}$, with and without epilepsy. ${ }^{11}$ Based on these findings, we proposed a difference in Z-score of $\geq 1$ to indicate a clinically significant reduction in BMD. In order to detect a Z-score difference of 1 with power of $0.8,16$ subjects were recruited in each group. ${ }^{12}$

\section{Data collection and determination of bone mineral density}

Upon entry, data were collected for age, gender, body weight, body height, body mass index (BMI) presence of contractures, skinfold thickness (triceps, lower biceps, and subscapular), and pubertal stage according to Tanner's classification. Weight-forage Z-score was calculated based on referenced data from a 1993 territory-wide growth survey of Hong Kong children. ${ }^{13}$ Blood taking was performed on the same day of DXA scan to evaluate calcium, phosphorous, alkaline phosphatase, transaminase, total protein, urea, creatinine, serum osmolality, and total cell count. A spot urine calcium-to-creatinine ratio $(\mathrm{mmol} / \mathrm{mmol})$ and urine calcium-to-osmolality ratio $(\mathrm{mg} / \mathrm{L}: \mathrm{mosmo} / \mathrm{kg})$ was also determined on the same day. Current dietary information was reviewed and daily calcium and vitamin D content were calculated by a dietitian.

In this study, BMD was determined by DXA of total body less head (TBLH) using a Lunar Prodigy Advance DXA bone densitometer (GE Healthcare, Madison [WI], US) with the latest Chinese children total BMD database installed. ${ }^{14,15}$ All subjects had BMD measured by the same validated densitometer to eliminate measurement error. Individual BMD value was expressed as $\mathrm{g} / \mathrm{cm}^{2}$ and Z-score. Z-score is the number of standard deviations of the patient's BMD above or below the average age- and sexmatched reference value. For the paediatric age-group, the current definition for osteoporosis includes BMD Z-score of $\leq-2.0$ adjusted for age, gender, and body size plus a clinically significant fracture defined in the International Society for Clinical Densitometry (ISCD) 2007 official positions. ${ }^{16}$ The head is disproportionately large in young children and may mask deficits at other skeletal sites, thus TBLH (subtotal/TBLH) BMD, which was recommended by ISCD 2007 official positions for the evaluation of child's bone health, was used in this study. For children with CP, TBLH BMD is more feasible and provides a holistic picture for BMD estimation.

\section{Statistical analyses}

\section{Effect of antiepileptic drugs on bone mineral density in non-ambulatory children with cerebral palsy}

In bivariate analysis, normally and non-normally distributed data were analysed by independent sample $t$ tests and Mann-Whitney $U$ tests, respectively. Categorical data were compared using Chi squared and Fisher's exact tests. Clinically relevant covariates (presence of puberty, daily calcium intake, and number of AED use) and the covariate (weight-for-age Z-score) approaching statistical significance $(\mathrm{P}<0.05)$ in bivariate analysis were entered into multivariable analysis (Enter Method). Statistical significance was defined as twotailed probability below 0.05 .

\section{Risk factors for low bone mineral density in non- ambulatory children with cerebral palsy}

Data of TBLH were split into low-BMD group versus normal-BMD group-those with TBLH Z-score of $\leq-2.0$ were considered to have low BMD. Baseline characteristics of the low- and normal-BMD groups were compared. Multivariable logistic regression analysis was used to examine the independent effect of puberty, weight-for-age Z-score (gender adjusted), number of AEDs, and daily calcium intake on TBLH Z-score.

All statistical analyses were performed using the Statistical Package for the Social Sciences (Windows version 13.0; SPSS Inc, Chicago [IL], US). The study was approved by the Ethics Committee of Kowloon West Cluster of Hospital Authority, Hong Kong. Informed consent was obtained from respective parents or the legal guardians from the Social Welfare Department, Government of the Hong Kong Special Administrative Region.

\section{Results}

Effect of antiepileptic drugs on bone mineral density in non-ambulatory children with cerebral palsy

The subjects were enrolled from 1 October 2012 to 30 September 2013 in DDU. Sixty-two children with CP aged 5 to 19 years were identified. Informed consent was obtained from a legal guardian for 44 patients of whom 12 were excluded from study-four had a history of fracture, two had severe deformity making DXA technically difficult, one had poorly controlled asthma and required long-term steroid therapy, and five had deranged liver or renal function. Of the remaining 32 children and adolescents, 18 (6 males, 12 females) aged 5.0 to 19.5 (mean \pm standard deviation, $13.8 \pm 4.7$ ) years comprised the study group. The control group consisted of 14 children and adolescents ( 6 males, 8 females) aged 7.0 to 19.1 (mean, 16.4 \pm 3.0 ) years.

Among the 18 subjects in the study group, eight were prescribed one AED and 10 were prescribed two or more. Sodium valproate was prescribed to eight children, carbamazepine to three, topiramate to three, phenobarbitone to five, phenytoin to one, and lamotrigine to four. In view of the limited population 
size, the impact of individual anticonvulsants was not analysed.

The two groups showed no significant difference in age, gender, BMI, weight-for-age Zscore, CP type, daily calcium intake, or daily vitamin D intake (Table 1).

Twelve (67\%) patients in the study group were in puberty, compared with $13(93 \%)$ patients in the control group $(\mathrm{P}=0.104)$. Sixteen $(89 \%)$ patients in the study group were tube feeders compared with four $(29 \%)$ in the control group $(\mathrm{P}=0.001)$. Among the oral feeders, all were reported by their caretaker to have a satisfactory dietary intake. Mean weight- for-age Z-score showed no significant difference between the study and control groups $(\mathrm{P}=0.226)$ [Table 1]. There was also no significant difference in the TBLH Z-scores $(\mathrm{P}=0.989$; Table 1$)$ or biochemical parameters of bone metabolism between the two groups (Table 2).

Low BMD was defined as TBLH Z-score of $\leq-2.0$ and was evident in 18 (56\%) patients. When comparing groups with low and normal BMD, there was no significant difference on univariate analysis in gender, age, CP, BMI, feeding mode, use of AEDs, puberty, or daily calcium and vitamin $\mathrm{D}$ intake (Table 3). Weight-for-age Z-score was significantly

TABLE I. Comparison of clinical characteristics and TBLH Z-score in children prescribed anticonvulsants (study group) and those not (control group)

\begin{tabular}{|c|c|c|c|}
\hline \multirow[t]{2}{*}{ Characteristic / TBLH Z-score } & \multicolumn{2}{|c|}{ Data* } & \multirow[t]{2}{*}{$P$ value } \\
\hline & Study group $(n=18)$ & Control group $(n=14)$ & \\
\hline Female:male & $12: 6$ & $8: 6$ & 0.581 \\
\hline Mean age (years) & 13.8 (5.0 to 19.5$)$ & $16.4(7.0$ to 19.1$)$ & 0.065 \\
\hline $\mathrm{BMI}\left(\mathrm{kg} / \mathrm{m}^{2}\right)$ & 16.8 (11.0 to 22.8 ) & 16.6 (12.8 to 25.9$)$ & 0.907 \\
\hline Weight-for-age Z-score & $-1.70(-3.19$ to -1.12$)$ & $-2.25(-3.80$ to -0.82$)$ & 0.226 \\
\hline \multicolumn{4}{|l|}{ Cerebral palsy } \\
\hline Spastic & $8(44)$ & $7(50)$ & 0.755 \\
\hline Dyskinetic/mixed & $10(56)$ & $7(50)$ & \\
\hline Puberty & $12(67)$ & $13(93)$ & 0.104 \\
\hline Prepubertal & $6(33)$ & $1(7)$ & \\
\hline \multicolumn{4}{|l|}{ Feeding practice } \\
\hline Tube feeding & $16(89)$ & $4(29)$ & $0.001 \dagger$ \\
\hline Oral feeding & $2(11)$ & $10(71)$ & \\
\hline Daily calcium intake (mg) & $1067 \pm 362.4$ & $1210 \pm 526.4$ & 0.371 \\
\hline Daily vitamin $D$ intake (IU) & $564 \pm 260.5$ & $609 \pm 396.3$ & 0.702 \\
\hline TBLH Z-score & $-2.44(-4.6$ to -0.3$)$ & $-2.55(-3.8$ to -1.2$)$ & 0.989 \\
\hline
\end{tabular}

Abbreviations: $\mathrm{BMI}=$ body mass index; TBLH = total body less head

* Data are shown as No., No. (\%), mean (range), or mean \pm standard deviation

$\dagger$ Fisher's exact test

TABLE 2. Comparison of biochemical parameters of bone metabolism in children prescribed anticonvulsants (study group) and those not (control group)

\begin{tabular}{lccc}
\hline \multirow{2}{*}{ Biochemical parameter } & \multicolumn{2}{c}{ Mean (range) } & \multirow{2}{*}{ P valueł } \\
\cline { 2 - 3 } & Study group $(\mathbf{n = 1 8})$ & Control group $(\mathbf{n = 1 4 )}$ & \\
\hline Alkaline phosphatase $(\mathrm{U} / \mathrm{L})$ & $136.8(59-232)$ & $133.4(71-217)$ & 0.856 \\
Calcium $(\mathrm{mmol} / \mathrm{L})$ & $2.30(2.14-2.44)$ & $2.33(2.14-2.43)$ & 0.246 \\
Phosphate $(\mathrm{mmol} / \mathrm{L})$ & $1.24(0.92-1.71)$ & $1.37(1.01-1.83)$ & 0.140 \\
Urine test & & & 0.499 \\
Calcium-to-creatinine ratio $(\mathrm{mmol} / \mathrm{mmol})^{*}$ & $0.36(0.09-0.87)$ & $0.41(0.1-0.69)$ & 0.925 \\
\hline Calcium-to-osmolality ratio $(\mathrm{mg} / \mathrm{L} / \mathrm{mosmo} / \mathrm{kg}) \dagger$ & $0.19(0.07-0.43)$ & $0.19(0.05-0.43)$ & \\
\hline
\end{tabular}

* Value $>0.7$ denotes hypercalciuria

$\dagger$ It is more accurate in patients with reduced muscle mass, value $>0.25$ denotes hypercalciuria

‡ Independent sample $t$ tests 
TABLE 3. Comparison of clinical characteristics and use of anticonvulsants between children with low and normal BMD

\begin{tabular}{|c|c|c|c|}
\hline \multirow[t]{2}{*}{ Characteristic / use of anticonvulsants } & \multicolumn{2}{|c|}{ Data* $^{*}$} & \multirow[t]{2}{*}{$P$ value } \\
\hline & Low-BMD group $(n=18)$ & Normal-BMD group $(n=14)$ & \\
\hline Female:male & 9:9 & $11: 3$ & 0.098 \\
\hline Age (years) & 16.0 (7.0 to 19.5$)$ & $13.6(5.0$ to 19.1$)$ & 0.138 \\
\hline $\mathrm{BMI}\left(\mathrm{kg} / \mathrm{m}^{2}\right)$ & 16.41 (12.52 to 22.76$)$ & 17.10 (11.00 to 25.94$)$ & 0.544 \\
\hline Weight-for-age Z-score & $-2.57(-3.80$ to -1.07$)$ & $-1.12(-2.44$ to -1.12$)$ & 0.001 \\
\hline \multicolumn{4}{|l|}{ Cerebral palsy } \\
\hline Spastic & $9(50 \%)$ & $6(43 \%)$ & 0.668 \\
\hline Dyskinetic / mixed & $9(50 \%)$ & $8(57 \%)$ & \\
\hline Puberty & $15(83 \%)$ & $10(71 \%)$ & 0.669 \\
\hline Prepubertal & $3(17 \%)$ & $4(29 \%)$ & \\
\hline \multicolumn{4}{|l|}{ Feeding practice } \\
\hline Tube feeding & $12(67 \%)$ & $8(57 \%)$ & 0.581 \\
\hline Oral feeding & $6(33 \%)$ & $6(43 \%)$ & \\
\hline Daily calcium intake (mg) & $1208 \pm 393$ & $1027 \pm 484$ & 0.257 \\
\hline Daily vitamin D intake (IU) & $637 \pm 276$ & $515 \pm 372$ & 0.297 \\
\hline Anticonvulsant use & $9(50 \%)$ & $9(64 \%)$ & 0.721 \\
\hline Monotherapy & 4 & 4 & \\
\hline$\geq 2$ Anticonvulsants & 5 & 5 & \\
\hline Calcium-to-osmolality ratio (mg/L/mosmo/kg) & $0.20 \pm 0.08$ & $0.18 \pm 0.11$ & 0.59 \\
\hline
\end{tabular}

Abbreviations: $\mathrm{BMD}=$ bone mineral density; $\mathrm{BMI}=$ body mass index

* Data are shown as No., No. (\%), mean (range), or mean \pm standard deviation

TABLE 4. Multivariate analysis of potential factors affecting TBLH BMD Z-score*

\begin{tabular}{lccc}
\hline Covariate & Adjusted OR & $\mathbf{9 5 \% ~ C l ~}$ & P value \\
\hline Puberty & 0.027 & $0.001-0.948$ & 0.047 \\
Weight-for-age Z-score & 0.015 & $0.001-0.390$ & 0.012 \\
No. of anticonvulsants used & 0.594 & $0.163-2.165$ & 0.430 \\
Daily calcium intake & 0.997 & $0.993-1.000$ & 0.063 \\
\hline
\end{tabular}

Abbreviations: $\mathrm{BMD}=$ bone mineral density; $\mathrm{Cl}=$ confidence interval; $\mathrm{OR}=$ odds ratio; TBLH = total body less head

* Hosmer-Lemeshow goodness of fit test ( $\mathrm{P}=0.3$ I 5$)$; Nagelkerke $\mathrm{R}^{2}=0.677$

lower $(-2.57$ vs $-1.12 ; \mathrm{P}=0.001)$ in the low BMD group (Table 3).

When covariates including weight-for-age Zscore, presence of puberty, daily calcium intake, and number of AEDs used were analysed by multiple logistic regression, higher weight-for-age Z-score (adjusted odds ratio $[\mathrm{OR}]=0.015 ; 95 \%$ confidence interval $[\mathrm{CI}], 0.001-0.390)$ and presence of puberty (adjusted OR=0.027; 95\% CI, 0.001-0.948) remained significant independent predictors for occurrence of a relatively normal BMD (ie TBLH Z-score $>2.0$ ). Hosmer-Lemeshow goodness of fit test $(\mathrm{P}=0.315)$ was non-significant, indicating a model prediction that was not significantly different to observed values. Nagelkerke $R^{2}$ was 0.677 , again signifying a relatively well-fitting model (Table 4).

\section{Discussion}

In the present study, DXA evaluation in nonambulatory children with $\mathrm{CP}$, with or without AED use, revealed a low BMD in $56 \%$ of those who underwent DXA. This is concordant with the findings in previous studies ${ }^{4,17-19}$ with prevalence of low BMD ranging from $27 \%$ to $77 \%$. Low BMD is the proximate cause of low-energy fracture in this group of children. Other factors such as stiff joints, poor balance leading to falls, and violent seizures may also contribute. Nearly $20 \%$ of such children have sustained a femoral fracture at some point. ${ }^{20}$

The impact of AED on BMD was unclear in non-ambulatory children with CP. The physician often faces a dilemma in optimising anticonvulsant treatment in this group of children who are already at high risk of developing osteoporotic long bone fracture.

Early studies revealed that treatment with enzyme-inducing anticonvulsants-for example, phenytoin and phenobarbitone-may induce catabolism of 25-hydroxyvitamin D, leading to rickets. ${ }^{21,22}$ Recent research on the effect of AED on BMD is inconclusive, and the results are often 
confounded by methodological flaws. In a crosssectional study, Farhat et $\mathrm{al}^{5}$ measured the BMD in 71 ambulatory subjects who were prescribed AED for more than 6 months. Reduced BMD was found in adults $(n=42)$ but not children $(n=29)$. There was no control group and the findings were only compared with paediatric data from the manufacturer, rendering it difficult to detect any small but significant difference secondary to AED treatment. Ecevit et $\mathrm{al}^{23}$ measured femoral neck BMD in 31 healthy children and 33 subjects with idiopathic epilepsy treated with either carbamazepine $(n=17)$ or valproate $(n=16)$. Valproate but not carbamazepine monotherapy was associated with a significant reduction in BMD. In this study, however, more children had attained puberty in the control group $(n=13,93 \%)$ than in the AED group ( $n=12,67 \%)$, which may have confounded the results. Coppola et $\mathrm{al}^{9}$ compared the BMD of 96 children with epilepsy alone or in association with $\mathrm{CP}$ and/or mental retardation against a control group of 63 healthy ambulatory subjects. While univariate analysis illustrated a reduced BMD Z-score in the AED group, no difference was found after adjustment for ambulatory status, mental retardation, lack of physical activity, and BMI in multivariate analysis.

In this study, we focused on non-ambulatory children with CP and severe mental retardation. This is the population most vulnerable to pathological long bone fracture, with a lifetime risk estimated to be $20 \%$. This group of children is also prone to develop refractory epilepsy that requires multiple AEDs at high doses. By recruiting concomitant residents from the same facility as the control group, we minimised the confounding effect of factors that may contribute to low BMD, namely ambulatory status, physical activity, and nutritional status. Our findings support that long-term use of AED in this group of children does not have any significant adverse effect on BMD. Optimal pharmacological treatment can be pursued without jeopardising bone mineralisation.

In multivariable analysis, there was a significant association of BMD Z-score with the presence of puberty. This may be due to the physiology and time frame for bone mineralisation that surges in puberty and reaches a peak at 20 years of age. Variation in time of starting puberty was a confounding factor as BMD Z-score was adjusted for gender and age only.

This study was carried out in a single institution for disabled children in Hong Kong. Because of the need for sedation and exposure to radiation, guardians of children with more severe neurological disease tended not to consent for the study. Moreover, DXA could not be properly performed in patients with severe deformity. These children were not included in the study.

An inadequate number of patients in each group may have impacted the power of this study.
Nevertheless, the result showed a strong association for weight-for-age Z-score with TBLH BMD. We believe the association was highly statistically significant.

Children with CP are at risk of malnutrition that has a significant impact on linear growth, wound recovery, motor function, and even survival. In addition to poor linear growth, malnourished children with severe CP are likely to have poor bone mineralisation leading to painful pathological fracture. In a retrospective study of $107 \mathrm{CP}$ children (90 non-ambulatory), weight-for-age Z-score proved to be the best predictor of BMD Z-score. ${ }^{24}$ In the present study, we demonstrated a significant correlation of low weight-for-age Z-score with low BMD, with a relatively well-fitting model after adjusting for pubertal stage, calcium intake, and AED use. This is concordant with our previous findings in the same population in which there was a significant protective effect of increase in weightfor-age Z-score in reducing fracture risk (adjusted $\mathrm{OR}=0.41) .{ }^{10} \mathrm{~A}$ recent review of 32 cross-sectional, cohort, case-control, and randomised controlled trials suggested that reduced bone density, impaired bone growth, and vitamin D deficiency may be seen in children treated with anticonvulsants. ${ }^{25}$ In our study, individual vitamin D daily intake was calculated by dietitians. Sun exposure was limited in the institutional setting. Thus, we assumed that the calculated daily oral vitamin D intake correlated well with the serum vitamin D level. Although the daily vitamin D intake was similar in the low- and normal-BMD groups $(\mathrm{P}=0.297)$ as well as the study and control groups $(\mathrm{P}=0.702), 10$ out of 32 subjects in the study consumed less than the recommended daily vitamin D intake (400 IU/day). To improve BMD and decrease fracture risk, regular nutritional assessment is necessary to identify malnourished children. Supplementation of vitamin D and calcium should be considered if the calculated daily need cannot be met. A nutritional rehabilitation programme should be implemented to optimise weight-for-age Z-score. Early gastrostomy tube placement should be considered in children with poor oral feeding. In children with weight-for-age $\mathrm{Z}$ score of $\leq-2.0$, serial BMD measurements can help to identify severe osteoporosis before fracture occurs. This window of time allows implementation of intensive nutritional rehabilitation, pharmacological intervention, and precautions in handling to prevent fracture occurrence.

\section{Conclusion}

Use of AED in non-ambulatory children with CP is unlikely to pose a detrimental impact on BMD. A low weight-for-age Z-score is a significant independent risk factor predictive of low BMD. Optimising nutritional status in this group of children is 
paramount to improving bone mineralisation and thus decreasing pathological fracture.

\section{Acknowledgement}

The authors would like to thank Ms Geraldine Ng, dietitian of Caritas Medical Centre, for her arduous effort to assess dietary calcium and vitamin D intake for our study patients.

\section{Declaration}

All authors have disclosed no conflicts of interest.

\section{References}

1. Houlihan CM, Stevenson RD. Bone density in cerebral palsy. Phys Med Rehabil Clin N Am 2009;20:493-508.

2. Marshall D, Johnell O, Wedel H. Meta-analysis of how well measures of bone mineral density predict occurrence of osteoporotic fractures. BMJ 1996;312:1254-9.

3. Lee JJ, Lyne ED, Kleerekoper M, Logan MS, Belfi RA. Disorders of bone metabolism in severely handicapped children and young adults. Clin Orthop Relat Res 1989;245:297-302.

4. Henderson RC, Lark RK, Gurka MJ, et al. Bone density and metabolism in children and adolescents with moderate to severe cerebral palsy. Pediatrics 2002;110:e5.

5. Farhat G, Yamout B, Mikati MA, et al. Effect of antiepileptic drugs on bone density in ambulatory patients. Neurology 2002;58:1348-53.

6. Petty SJ, Paton LM, O'Brien TJ, et al. Effect of antiepileptic medication on bone mineral measures. Neurology 2005;65:1358-65.

7. Sheth RD, Wesolowski CA, Jacob JC, et al. Effect of carbamazepine and valproate on bone mineral density. J Pediatr 1995;127:256-62.

8. Triantafyllou N, Lambrinoudaki I, Armeni E, et al. Effect of long-term valproate monotherapy on bone mineral density in adults with epilepsy. J Neurol Sci 2010;290:131-4.

9. Coppola G. Fortunato D, Auricchio G, et al. Bone mineral density in children, adolescents, and young adults with epilepsy. Epilepsia 2009;50:2140-6.

10. Ko $\mathrm{CH}$, Tse PW, Chan AK. Risk factors of long bone fracture in non-ambulatory cerebral palsy children. Hong Kong Med J 2006;12:426-31.

11. Coppola G, Fortunato D, Mainolfi C, et al. Bone mineral density in a population of children and adolescents with cerebral palsy and mental retardation with or without epilepsy. Epilepsia 2012;53:2172-7.

12. Portney LG, Watkins MP. Foundations of clinical research applications to practice. 3rd ed. Upper Saddle River, NJ: Pearson/Prentice Hall; 2009: 832-47.

13. Leung SS, Lau JT, Tse LY, Oppenheimer SJ. Weight-for-age and weight-for-height references for Hong Kong children from birth to 18 years. J Paediatr Child Health 1996;32:1039.

14. Xu H, Chen JX, Gong J, et al. Normal reference for bone density in healthy Chinese children. J Clin Densitom 2008;10:266-75.

15. Guo B, Xu Y, Gong J, Tang Y, Xu H. Age trends of bone mineral density and percentile curves in healthy Chinese children and adolescents. J Bone Miner Metab 2013;31:30414.

16. Lewiecki EM, Gordon CM, Baim S, et al. International Society for Clinical Densitometry 2007 Adult and Pediatric Official Positions. Bone 2008;43:1115-21.

17. Hartman C, Brik R, Tamir A, Merrick J, Shamir R. Bone quantitative ultrasound and nutritional status in severely handicapped institutionalized children and adolescents. Clin Nutr 2004;23:89-98.

18. King W, Levin R, Schmidt R, Oestreich A, Heubi JE. Prevalence of reduced bone mass in children and adults with spastic quadriplegia. Dev Med Child Neurol 2003;45:12-6.

19. Ali O, Shim M, Fowler E, Cohen P, Oppenheim W. Spinal bone mineral density, IGF-1 and IGFBP-3 in children with cerebral palsy. Horm Res 2007;68:316-20.

20. Sturm PF, Alman BA, Christie BL. Femur fractures in institutionalized patients after hip spica immobilization. J Pediatr Orthop 1993;13:246-8.

21. Crosley CJ, Chee C, Berman PH. Rickets associated with long-term anticonvulsants therapy in a pediatric outpatient population. Pediatrics 1975;56:52-7.

22. Keck E, Gollnick B, Reinhardt D, Karch D, Peerenboom $\mathrm{H}$, Krüskemper HL. Calcium metabolism and vitamin D metabolite levels in children receiving anticonvulsant drugs. Eur J Pediatr 1982;139:52-5.

23. Ecevit C, Aydoğan A, Kavakli T, Altinöz S. Effect of carbamazepine and valproate on bone mineral density. Pediatr Neurol 2004;31:279-82.

24. Henderson RC, Kairalla J, Abbas A, Stevenson RD. Predicting low bone density in children and young adults with quadriplegic cerebral palsy. Dev Med Child Neurol 2004;46:416-9.

25. Vestergaard P. Effects of antiepileptic drugs on bone health and growth potential in children with epilepsy. Pediatr Drugs 2015;17:141-50. 